\title{
EVALUATION EFFICIENCY OF INTERMODAL TRANSPORT USING MULTI-CRITERIA ANALYSIS
}

\author{
Svetla Stoilova \\ Technical University-Sofia, Bulgaria \\ stoilova@tu-sofia.bg
}

\begin{abstract}
The subject of the study is two types of intermodal transport: container transport and accompanied intermodal Ro-La transports that the trucks are uploaded on special platform-wagons, and the drivers travel in a passenger wagon. When selecting the transport technology, operating costs are of major importance, but environmental, technological and other criteria also have an impact. In the study the methodology has been developed to evaluate the effectiveness of intermodal transport. The theory of multi-criteria decision making based on PROMETHEE (Preference ranking organization method for enrichment evaluation) methods has been applied. The methodology includes four steps. The first step defines the quantitative and qualitative criteria for the assessment of intermodal transport. The investigated strategies for transportation that have been studied are intermodal rail transport and road transport. The weighs of the criteria have been determined in the second step. The PROMETHEE multi-criteria analysis method has been applied in the third step for ranking the variants of transportation. The fourth step involves selecting an optimal transport technology by the optimisation criterion the minimum of ratio of the normalized cost and normalized net outranking flows determined by the PROMETHEE method. The methodology is approbated for the routes Sofia-Varna and Dragoman-Svilengrad from the railway and road network of Bulgaria. It was found that the technologies that include rail transport are the best variant of transportation. For the surveyed routes the minimal number of wagons in the train composition has been established that provide ecological efficiency, i.e. saving on emissions of pollutants from heavy goods vehicles.
\end{abstract}

Keywords: intermodal transport; PROMETHEE, Ro-La, block train, railway transport.

\section{Introduction}

The development of intermodal transport provides the opportunity to solve problems related to environmental protection. The intermodal organization of transport from start to finish point with congestion at intermodal terminals has strong competition in road freight. The aim is to release the road network from heavy goods and to develop rail transport as an ecological mode of transport.

The subject of the study is two types of intermodal transport: unaccompanied transport by container transport and accompanied intermodal transport (Ro-La: transport of heavy goods vehicles with specialized wagons). When selecting the transport technology, operating costs are of major importance, but environmental, technological and other criteria also have an impact. Therefore, it is necessary to develop a methodology that takes into account many factors affecting the transport process. The factors transport cost, transport time, flexibility, reliability, quality and sustainability have been established in [1] as key indicators in transport. The factors flexibility, safety and security, reliability, time, and accessibility are determined in [2] to assess intermodal terminals. In [3] the authors defined the quality and performance indicators for intermodal terminals. In [4-6] are investigated the problems of railway and road transport. In transport the methods of multi-criteria analysis as PROMETHEE Method have been used to determine the mode of transportation, to estimate the passenger satisfaction, to evaluate the transport projects, choice of alternative fuel for passenger cars and for other purposes [7-9].

The aim of the study is to develop a methodology based on the multi-criteria model for the selection of transport technology related to environmental protection.

\section{Materials and methods}

The methodology for evaluating the effectiveness of intermodal transport includes the following steps.

- Step 1: Definition of quantitative and qualitative criteria for the assessment of intermodal transport. In the research the following criteria defined in [6] are studied: S1: Environmental criterion; S2: Operational costs for intermodal transportation; S3: Transportation fare; S4: Infrastructure charges; S5: Duration of transportation; S6: Transport from door to door; S7: Duration of transhipment operations; S8: Comfort. In accompanied Ro-La transport truck 
drivers can relax during the journey in a separate car; S9: Security; S10: Reliability. This is means meeting the deadline for the delivery of cargo and accurate schedule of trains; S11: Stability. There is lack of dependence between intermodal transportation and the season.

- Step 2: Determining the weights of the criteria. This paper uses the weights of criteria that were determined by the author in [6] using the DEMATEL method.

- Step 3: Selection of variants of the transportation for a given route. In this research two types of intermodal transport are investigated: container transport and Ro-La transport. Carriage options include rail and road transport.

- Step 4: Choice of optimal variant of transportation. This step explores two strategies that differ in the type of the optimisation criterion for selecting the optimal transportation technology.

Strategy 1: The optimisation criterion is the maximum of outranking flows determined by the PROMETHEE method. This method is based on a comparison pair per pair of possible decisions along each criterion. Possible decisions are evaluated according to different criteria, which have to be maximized or minimized. The use of the PROMETHEE method requires two additional types of information for each criterion: a weight and a preference function. The preference function characterizes the difference for a criterion between the evaluations obtained by two possible decisions into a preference degree ranging from 0 to 1 . In order to ease the definition of these functions, six basic preference functions have been proposed in [10]. These functions are: usual criterion, quasi criterion, criterion with linear preference, level criterion, criterion with linear preference and indifference area, Gaussian criterion.

The optimisation model for Strategy 1 includes all determined criteria.

$$
\varphi_{i} \rightarrow \max , i=1, \ldots, n
$$

where $i$ - number of variants of transportation.

Strategy 2: The optimisation criterion is the ratio of the normalized costs and the normalized scores corresponding to the PROMETHEE priority. The minimal value of this ratio presents the optimal variant. In this case the model by the PROMETHEE method does not include the operating costs and infrastructure charge. These criteria are taken separately for each option. The optimisation model includes their normalized values.

The optimisation criterion is:

$$
r_{i}=\frac{c_{i}}{\varphi_{i}} \rightarrow \min
$$

where $c_{i}$-normalized values of operating costs and infrastructure taxes for variant $i$;

$\varphi_{i}$ - outranking flows determining by PROMETHEE method for variant $i$.

Step 4 includes the following stages:

- determination the values of the quantitative criteria for each option. Determination of carbon dioxide emissions (g), operating costs $\left(\right.$ BGN.Day $\left.^{-1}\right)$, infrastructure and vignette fees $\left(\right.$ BGN. day $\left.^{-1}\right)$, travel time (h). Qualitative criteria are set to "yes" and "no".

- normalization of total costs (operating costs and infrastructure charges).

- prioritisation of the variants using the PROMETHEE method. In this case the criteria do not include the operating costs and infrastructure charges.

The operating costs for container transport by rail - block trains are determined as follow:

$$
R_{o}^{F T}=L n c_{L}+L m c_{w}+m c_{k}, \mathrm{BGN} \cdot \operatorname{train}^{-1},
$$

where $L$ - length of the route, $\mathrm{km}$;

$n$ - number of locomotives in the train composition;

$m$ - number of wagons in the train composition;

$c_{L}-$ cost rate for one highway locomotive, BGN $\cdot$ lockm $^{-1}$, BGN is the Bulgarian currency;

lockm is transporting a locomotive per kilometre;

$c_{w}$ - cost rate for a freight wagon, BGN. wagkm ${ }^{-1}$;

$c_{L}=1.2 \mathrm{BGN} \cdot \operatorname{lockm}^{-1} ; c_{w}=0.2 \mathrm{BGN} \cdot \mathrm{wagkm}^{-1}$; (data are from BDZ Ltd); 
$c_{k}$ - costs of handling the container, BGN. container $^{-1} ; c_{k}=45$ euro, according to the tariff for transportation of goods by rail in Bulgaria.

To compare the results with the movement of the road train the operating costs of a freight train are determined for one road train $R_{o, R T}^{F T}$.

$$
R_{o, R T}^{F T}=\frac{R_{o}^{F T}}{m}, \mathrm{BGN} \cdot \mathrm{road} \operatorname{train}^{-1}
$$

Fuel consumption is the largest share of the transport company's operating costs. To determine the operating costs of an auto train the cost of tires, lubricants, maintenance, drivers' salaries, taxes and insurance and other types of costs should also be taken into account. In the European Truck Challenge 2014 [11] test, the following values were set for the operating costs: an average rate of $0.467 \mathrm{EUR} \cdot \mathrm{km}^{-1}$ for variable costs, and an average rate of fixed costs of $0.223 \mathrm{EUR} \cdot \mathrm{km}^{-1}$ or a total of 0.69 EUR $\mathrm{km}^{-1}$. In this case, fuel costs are $60 \%$ of the operating costs and $40 \%$ are the aforementioned operating cost groups and can be written:

$$
R_{o}^{F T}=R_{Q}+0.4 R_{Q}, \mathrm{BGN} \cdot \text { road train }{ }^{-1}
$$

where $R_{o}^{F T}$ - operating costs for road train, BGN. Road train ${ }^{-1}$;

$R_{Q}$ - fuel costs for a given route,BGN. Road train ${ }^{-1}$;

0.4 - coefficient for accounting for the other components of the operating costs.

The operating costs for freight train for Ro-La technology are:

$$
R_{o}^{R o-L a}=1.1\left(L n c_{L}+L m c_{w}\right)+n\left(c_{b}+c_{m}\right), \mathrm{BGN} \cdot \operatorname{train}^{-1}
$$

where $c_{b}$ - price of the ticket; $c_{b}=15$ BGN.pass. ${ }^{-1}$, according to the BDZ Passenger Transport Tariff;

$c_{m}$ - price of the ticket for wagon-lit, BGN.; $c_{m}=10 \mathrm{BGN} \cdot$ pass $^{-1}$;

1.1 - coefficient that takes into account the cost of using the loading/unloading site of the road train.

The number of drivers is equal to the number of heavy-duty vehicles.

- Step 5. Determination of the optimal variant. The strategy that sets the optimal solution is Strategy 2, which applies a complex optimisation criterion. The results of Strategy 1 analyse the adequacy of the decision that was taken.

\section{Results and discussion}

The methodology is approved for container transport by rail and road for direction Sofia-Varna and for intermodal transport Ro-La and road transport for the direction Dragoman-Svilengrad.

In the area of Sofia there are private terminals, which could carry out container transport. Near the railway station Dragoman there is an intermodal rail terminal for accompanying freight transport in the direction of Dragoman-Sofia-Plovdiv-Svilengrad. It has two tracks with a useful length of each $300 \mathrm{~m}$. At this time, the intermodal terminal is not used. An intermodal rail terminal for accompanying freight transport is also built at Svilengrad station. The destination is characterized by a significant volume of transit traffic flows passing through Bulgaria to Turkey.

\section{Container transport by rail - block trains}

The direction of Sofia-Varna was chosen for experimentation of the methodology for assesses the efficiency of container block trains. Transport by road train and railway transport were studied.

As intermodal transport is operated with more than one transport, the cost of transport from the initial loading points of the containers to the container terminal and from the container terminal to the final delivery points is not taken into account when conducting the study.

Freight trains consist of 20 wagons (container wagons - Rgs, tare $24 \mathrm{t}$ ), locomotive 46 and 43 series, gross train weight $1086 \mathrm{t}$. Gross mass per wagon $-44 \mathrm{t}$, gross mass of the locomotive 
46 series $-120 \mathrm{t}$, the locomotive 43 series $-80 \mathrm{t}$. Wagons are loaded with 40 -foot containers with gross mass $20 \mathrm{t}$.

In order to determine the amount of carbon dioxide emitted by road traffic on the routes the data from the actual European Truck Challenge 2014 test [11], which found CO2 emissions based on a payload of $49.54 \mathrm{~g} \cdot(\mathrm{tkm})^{-1}$, were used. The road train are Euro 6 standard.

The variants of transportation are, Fig. 1:

- Transportation by railway transport. In the paper two alternative routes are investigated:

Variant 1 - Freight block train (FT1): Iliyantsi-Gorna Oryahovitsa-Varna;

Variant 2 - Freight block train (FT2): Iliantsi-Karlovo-Karnobat-Varna.

- Transportation by road train. In the paper three alternative routes are investigated:

Variant 3 - Route R1: Road train (RT1) Sofia-Veliko Tarnovo-Varna;

Variant 4 - Route R2: Road train (RT2) Sofia-Plovdiv-Burgas-Varna;

Variant 5 - Route R3: Road train (RT3) Sofia-Plovdiv-Karnobat-Shumen-Varna.

Table 1 shows the parameters for the model. The weights of criteria are determined by the author in [6]. The vignette fees for the road trains are defined for the use of an annual vignette and for transport twice a week.

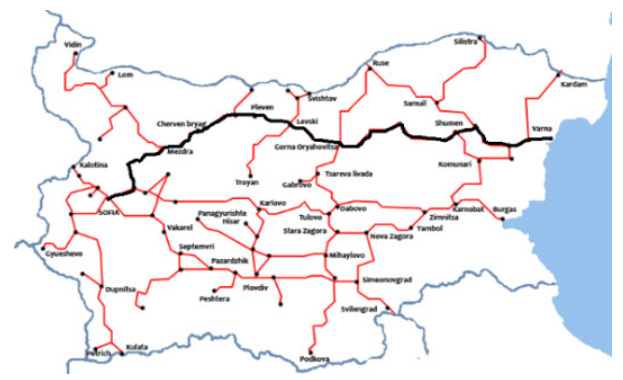

(FT1) Iliyantsi-Gorna Oryahovitsa-Varna

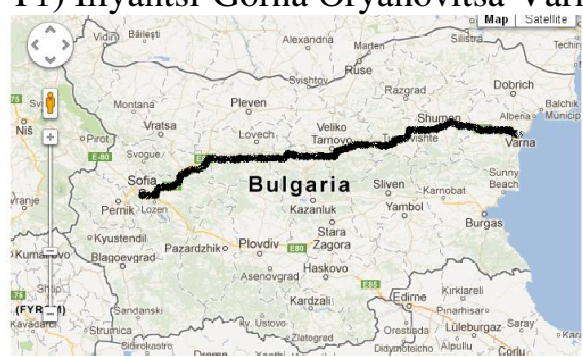

(RT1) Sofia-Veliko Tarnovo-Varna

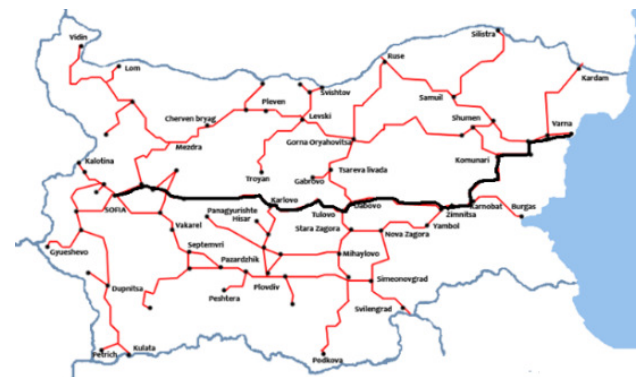

(FT2) Iliantsi-Karlovo-Karnobat-Varna

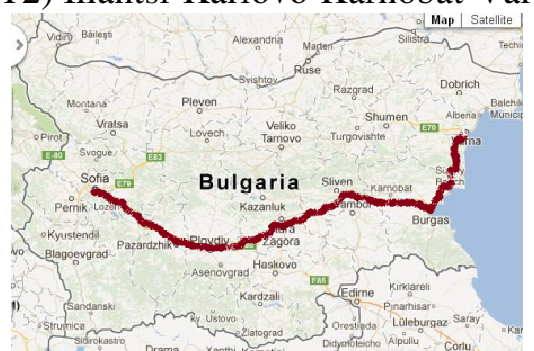

(RT2) Sofia-Plovdiv-Burgas-Varna

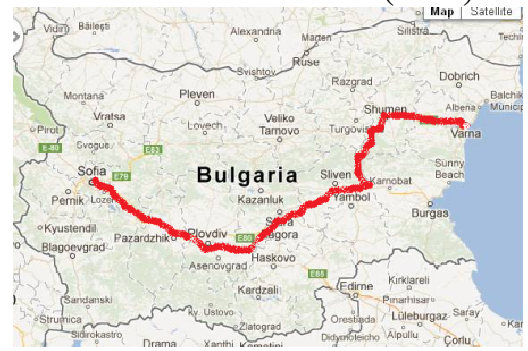

(RT3) Sofia-Plovdiv-Karnobat-Shumen-Varna

Fig. 1. Maps of variants of transportation

The criterion S3 and criteria from S6 to S11 are set with "yes"and "no", as follows:

1. S3 (Transportation fare) is set "yes" for all variants with railway transport (FT1 and FT2). For variants with road train S3 are set with "no".

2. S6 (Transportfromdoortodoor)issetwith"yes" for all variants taking into account that intermodal transport and transportation with road train realized carriage door to door.

3. S7 (Duration of transhipment operations) is set with "yes"for all variants with railway transport, since there is overload at an intermodal terminal. Road haulage is presumed to be carried out from the warehouse of the shipper. 
4. S8 (Comfort) issetwith"yes"for all variants. This criterion takes into account the comfortable travel and relaxation for accompanied intermodal transport by technology Ro-La.

5. S9 (Security) set"yes" for all variants with railway transport, given the higher safety of this mode of transport and the number of road accidents.

6. S10 (Reliability) is set"yes"for rail transport, taking into account the implementation of the train timetable.

7. S11 (Stability) is set "yes" for rail transport, taking into account the impact of the weather conditions on transport operations.

Table 1

Values of criteria for investigated variants

\begin{tabular}{|c|c|c|c|c|c|c|c|c|}
\hline \multirow{3}{*}{ Criteria } & \multirow{4}{*}{ Weight } & \multirow{2}{*}{\multicolumn{2}{|c|}{$\frac{1}{\text { FT1 }}$}} & \multirow{2}{*}{\multicolumn{2}{|c|}{$\frac{2}{\text { FT2 }}$}} & 3 & 4 & 5 \\
\hline & & & & & & \multirow{2}{*}{ RT1 } & \multirow{2}{*}{ RT2 } & \multirow{2}{*}{ RT3 } \\
\hline & & For FT & For RT & For FT & For RT & & & \\
\hline Length, km & & 543 & 543 & 514 & 514 & 447 & 524 & 551 \\
\hline $\begin{array}{l}\text { S1:Environmental } \\
\text { criterion, } \mathrm{CO} 2, \mathrm{~g}\end{array}$ & 0.08 & 4765140 & 238257 & 4945000 & 247250 & 442887 & 519180 & 545931 \\
\hline $\begin{array}{l}\text { S2: Operational } \\
\text { costs, BGN. }\end{array}$ & 0.19 & 5275.2 & 263.76 & 5089.6 & 254.48 & 379 & 454.44 & 378 \\
\hline $\begin{array}{c}\text { S3:Transportation } \\
\text { fare }\end{array}$ & 0.09 & yes & yes & yes & yes & no & no & no \\
\hline $\begin{array}{l}\text { S4: Infrastructure } \\
\text { charges, BGN }\end{array}$ & 0.07 & 3346.56 & 167.33 & 3167.83 & 158.39 & 12.41 & 12.41 & 12.41 \\
\hline $\begin{array}{c}\text { S5: } \\
\text { Duration of } \\
\text { transportation ,h }\end{array}$ & 0.13 & 9.05 & 9.05 & 8.57 & 8.57 & 7.14 & 8.12 & 8.62 \\
\hline $\begin{array}{l}\text { S6:Transport from } \\
\text { door to door }\end{array}$ & 0.12 & yes & yes & yes & yes & yes & yes & yes \\
\hline $\begin{array}{c}\text { S7:Duration of } \\
\text { transhipment } \\
\text { operations }\end{array}$ & 0.06 & yes & yes & yes & yes & no & no & no \\
\hline S8:Comfort & 0.08 & yes & yes & yes & yes & yes & yes & yes \\
\hline S9:Security & 0.07 & yes & yes & yes & yes & no & no & no \\
\hline S10:Reliability & 0.05 & yes & yes & yes & yes & no & no & no \\
\hline S11:Stability & 0.04 & yes & yes & yes & yes & no & no & no \\
\hline
\end{tabular}

Table 2 presents the type of optimisation for each criterion.

Table 2

Type of optimisation

\begin{tabular}{|c|c|c|c|c|c|c|c|c|c|c|c|}
\hline Criterion & S1 & S2 & S3 & S4 & S5 & S6 & S7 & S8 & S9 & S10 & S11 \\
\hline $\begin{array}{c}\text { Type of } \\
\text { Optimisation }\end{array}$ & $\min$ & $\min$ & $\min$ & $\min$ & $\min$ & $\max$ & $\min$ & $\max$ & $\max$ & $\max$ & $\max$ \\
\hline
\end{tabular}

To do the research software Visual PROMETHEE is used. When performing the optimisation with software Visual PROMETHEE, "yes" and "no" are set to 1 and 0.

Strategy 1:The optimisation criterion is the maximum of outranking flows determined by the PROMETHEE method.

Fig. 2 presents the prioritisation of variants in Visual PROMETHEE according to outranking flows. The figure consists two diagrams. The first diagram shows the prioritisation. The second diagram shows the weights of the criteria in percents. The highest value of outranking flows is for the 
intermodal transport - block trains on the route Sofia-Karlovo-Varna. The third position is for the transport with block trains on the route Sofia-Gorna Oryahovitsa-Varna.
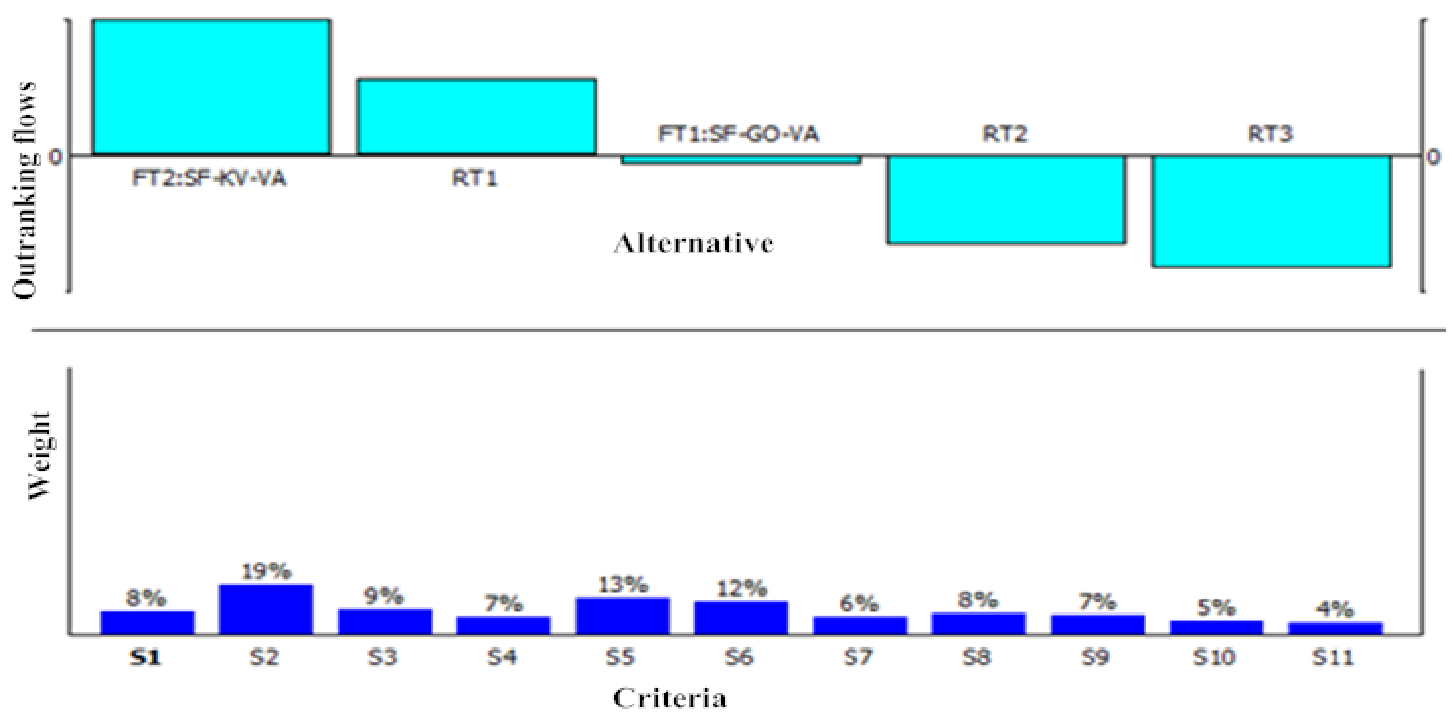

Fig. 2. Prioritisation of variants in Visual PROMETHEE - Strategy 1

When changing the weight of the criterion S1 (Ecological Criteria, CO2) above $19.95 \%$, the transport with container block trains on the route Sofia-Gorna Oryahovitsa-Varna is in the second position, i.e. both railways have the highest priority. The results obtained for Strategy 1 remain unchanged taking into account the vignette fee for a different time period (daily, monthly, weekly, annual vignette). The reporting of the operating costs and infrastructure costs together with the other criteria in the general model does not allow to take into account the sensitivity of the variation of vignette fees to the choice of the optimal variant of transport.

Table 3 shows the limits of the change of the criteria values, for which the transport with block trains has the highest priority. The ecological criteria (S1), transportation fare (S3), infrastructure charges (S4), duration of transportation (S5) and duration of transhipment operations (S7) are most sensitive.

Table 3

Stability intervals for Strategy 1

\begin{tabular}{|c|c|c|c|c|c|c|c|c|c|c|c|}
\hline Criterion & S1 & S2 & S3 & S4 & S5 & S6 & S7 & S8 & S9 & S10 & S11 \\
\hline From, $\%$ & 2.48 & 12.66 & 0 & 0 & 0 & 0 & 0 & 0 & 0.08 & 0 & 0 \\
\hline To, $\%$ & 32.12 & 100 & 15.35 & 14.31 & 20.55 & 100 & 12.77 & 100 & 100 & 100 & 100 \\
\hline
\end{tabular}

Strategy2: The choice of optimal transportation technology is made on a complex criterion - the minimum ratio of normalized costs and normalized net outflows. The prioritisation of variants of transportation is shown in Fig. 3. The highest value of the outranking flows is again for the intermodal transport - block trains on the route Sofia-Karlovo-Varna.

Optimisation using the PROMETHEE method does not include the economic criteria. The weights of the criteria included in the PROMETHEE optimisation model are determined as the weights of the economic criteria added proportionally to the weights established by the DEAMATEL method. Table 4 shows the limits of the change of the criteria, values for which the transport with block trains has the highest priority. The ecological criteria (S1), duration of transportation (S5) and duration of transhipment operations (S7) are most sensitive.

Table 4

Stability intervals for Strategy 2

\begin{tabular}{|c|c|c|c|c|c|c|c|c|}
\hline Criterion & S1 & S5 & S6 & S7 & S8 & S9 & S10 & S11 \\
\hline From, $\%$ & 2.48 & 7.56 & 0 & 0 & 0 & 7.13 & 3.84 & 2.16 \\
\hline To, $\%$ & 32.12 & 24.65 & 100 & 13.65 & 100 & 100 & 100 & 100 \\
\hline
\end{tabular}



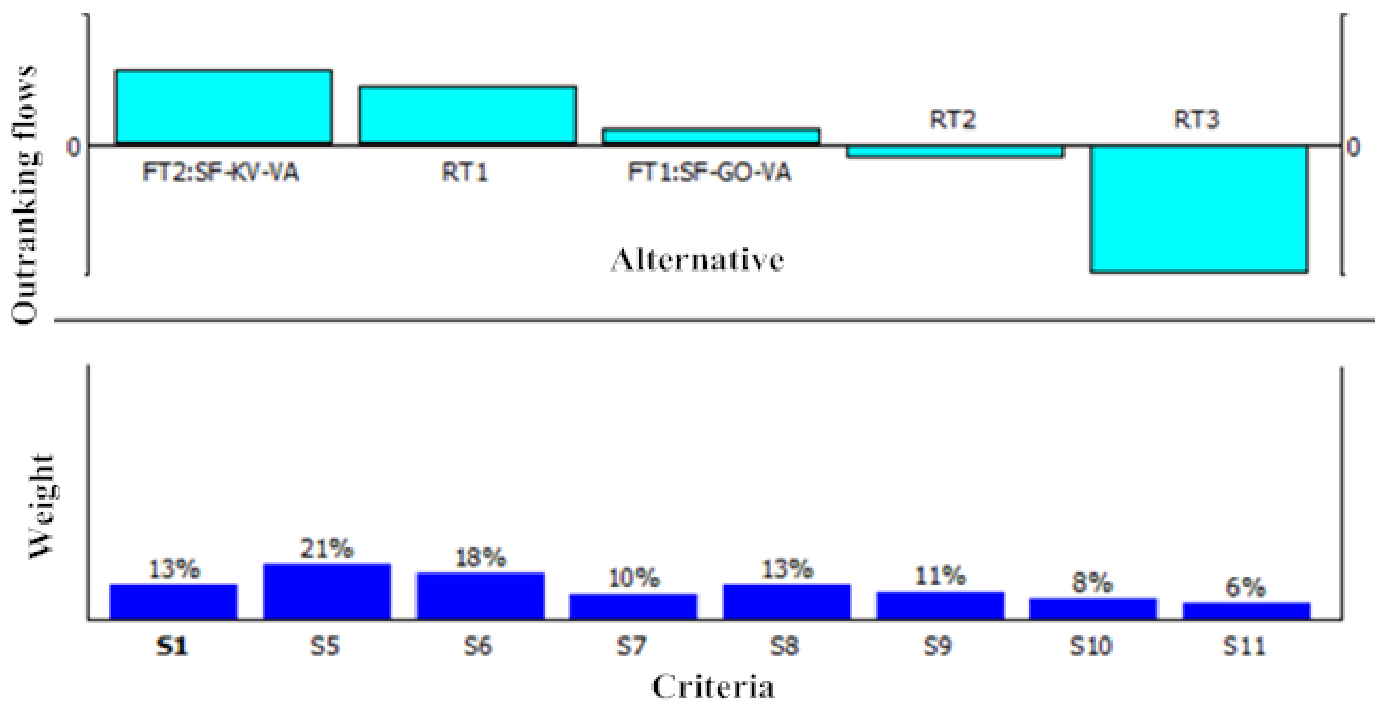

Fig. 3. Prioritisation of variants in Visual PROMETHEE - Strategy 2

For rail freight transport, the infrastructure charges are set for a train depending on the length of the route and the gross mass. For transport by road vignette charges are paid, which can be for different periods of time (day, week, month or year). To take account of the difference in the charges for rail and road transport variants for assessing the impact of vignette charges over the selection of optimal transport are studied. The variants are:

- Variant 1: The costs do not take into account infrastructure charges (road vignette).

The following variants are investigated depending on the use of daily, weekly, monthly or annual vignette, and the number of trips:

- Variant 2: Daily vignette;

- Variant 3: Weekly vignette. Transportation 2 times a week;

- Variant 4: Weekly vignette. Transportation 3 times a week;

- Variant 5: Weekly vignette. Transportation 4 times a week;

- Variant 6: Weekly vignette. Transportation 5 times a week;

- Variant 7: Monthly vignette. Transportation 1 times a week;

- Variant 8: Monthly vignette. Transportation 2 times a week;

- Variant 9: Annual vignette. Transportation 1 time a week;

- Variant 10: Annual vignette. Transportation 2 times a week;

- Variant 11: Annual vignette. Transportation 5 times a week.

Figure 4 presents the results of the optimisation criterion defined by formula (2) for all variants. The second strategy makes it possible to take into account the dynamics of changes in the components of costs, such as operating costs and infrastructure charges, when choosing the optimal variant of transportation. The study shows that the amount of vignette taxes has an impact on the prioritisation of transport alternatives.

The results show the following.

- When infrastructure charges (vignettes) are not taken into account in the costs, the optimal transport technology is transport with container block trains.

- Transportation with container block trains is the optimal variant for the following cases: a weekly vignette is used and the carriage is performed twice a week; monthly vignette is used and the carriage is performed once a week.

- Transportation by road trains Sofia-Veliko Tarnovo-Varna is the optimal transport technology for the following cases: daily vignette is used; weekly vignette is used and the trips are carried out three times a week; monthly vignette is used and the trips are carried out over twice a week; an annual vignette is used. 
- The results for transports with block trains and road trains on the route Sofia-Veliko TarnovoVarna are close.

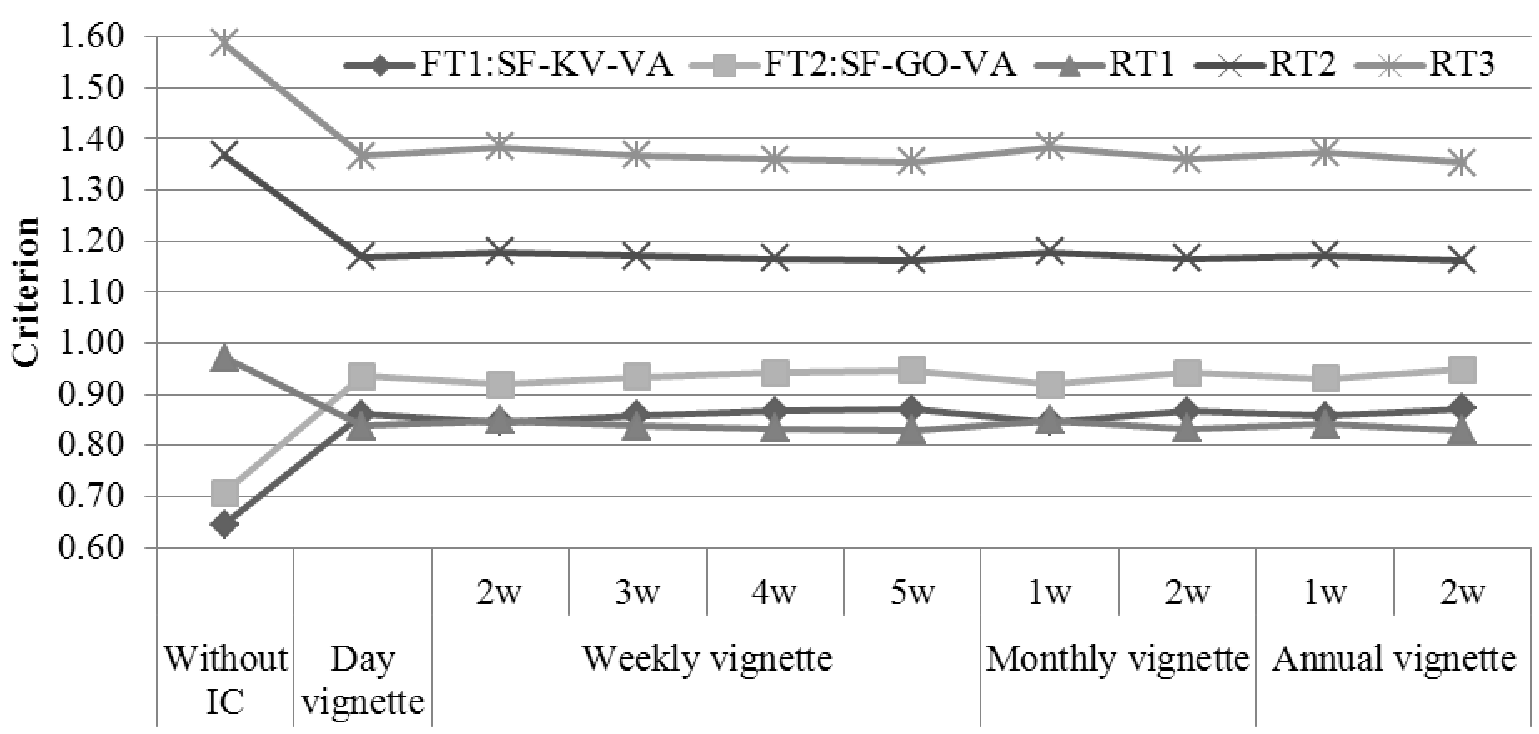

\section{Variant}

Fig. 4. Comparison of results for different variants of use of vignette for road train

The obtained results show that, when the vignette charges for road transport increase, the optimal transport technology will be transport with container block trains.

To assess the environmental efficiency in the transport of container block trains, in the research the influence of the number of wagons in the train composition on the saved emissions is studied.

The results show that trains with a composition of more than 11 wagons are eco-efficient.

The results show that for Strategy 1 the optimal transport technology is transportation with container block trains. For Strategy 2, which applies a complex optimisation criterion, rail and road transport have similar results. With an increase of vignette charges for road trains, the optimal transport technology is transport of container block trains.

\section{Accompanying intermodal transport Ro-La}

The developed methodology has been experimented for the assessment of transport along the route Dimitrovgrad-Svilengrad. At both points, there is a site for Ro-La transport operations under the transport scheme. Freight trains consist of 20 wagons for carriage of heavy goods vehicles, 1 wagon for transport of car drivers; locomotive 46 and 43 series, gross train weight $1441 \mathrm{t}$. Gross weight per wagon $-60 \mathrm{t}$, gross weight of the passenger car $-35 \mathrm{t}$; gross weight of the locomotive 46 series $120 \mathrm{t}$, the locomotive 43 series $-80 \mathrm{t}$. Wagons are loaded with trains under the transportation technology.

Table 5 presents the values of the criteria for the investigated variants for both, the technology Ro-La and road train. The data for road train are for the case of usage weekly vignette and carriage twice a week.

Table 5

Ro-La Transportation

\begin{tabular}{|c|c|c|c|c|}
\hline Variant & \multirow{3}{*}{ Weight } & \multicolumn{3}{|c|}{ Direction Dragoman - Svilengrad } \\
\cline { 4 - 5 } & & FT:Ro-La & $\begin{array}{c}\text { FT:Ro-La } \\
\text { For 1RT }\end{array}$ & RT \\
\cline { 3 - 5 } & & $342 \mathrm{~km}$ & $342 \mathrm{~km}$ & $330 \mathrm{~km}$ \\
\hline S1:Environmental criterion, CO2, g & 0.08 & 4738000 & 236900 & 326964 \\
\hline S2: Operational costs, BGN. & 0.19 & 2683 & 134.15 & 317.88 \\
\hline S3:Transportation fare & 0.09 & yes & yes & no \\
\hline
\end{tabular}


Table 5 (continued)

\begin{tabular}{|c|c|c|c|c|}
\hline Variant & \multirow{2}{*}{ Weight } & \multicolumn{3}{|c|}{ Direction Dragoman - Svilengrad } \\
\cline { 4 - 5 } Criteria & & FT:Ro-La & $\begin{array}{c}\text { FT:Ro-La } \\
\text { For 1RT }\end{array}$ & RT \\
\hline S4: Infrastructure charges, BGN & 0.07 & 1472.37 & 73.61 & 33.5 \\
\hline S5:Duration of transportation, $\mathrm{h}$ & 0.13 & 7 & 7 & 5.8 \\
\hline S6:Transport from door to door & 0.12 & yes & yes & yes \\
\hline S7:Duration of transhipment operations & 0.06 & yes & yes & no \\
\hline S8:Comfort & 0.08 & yes & yes & no \\
\hline S9:Security & 0.07 & yes & yes & no \\
\hline S10:Reliability & 0.05 & yes & yes & no \\
\hline S11:Stability & 0.04 & yes & yes & no \\
\hline
\end{tabular}

The study was conducted on both strategies according to the usage of the vignette fee and reporting of the infrastructure (vignette) fees. Figure 5 shows the results of the optimisation criterion according to the usage of vignette for a given period of time. The results show that the technology RO$\mathrm{La}$ is the optimal transport for all investigated variants.

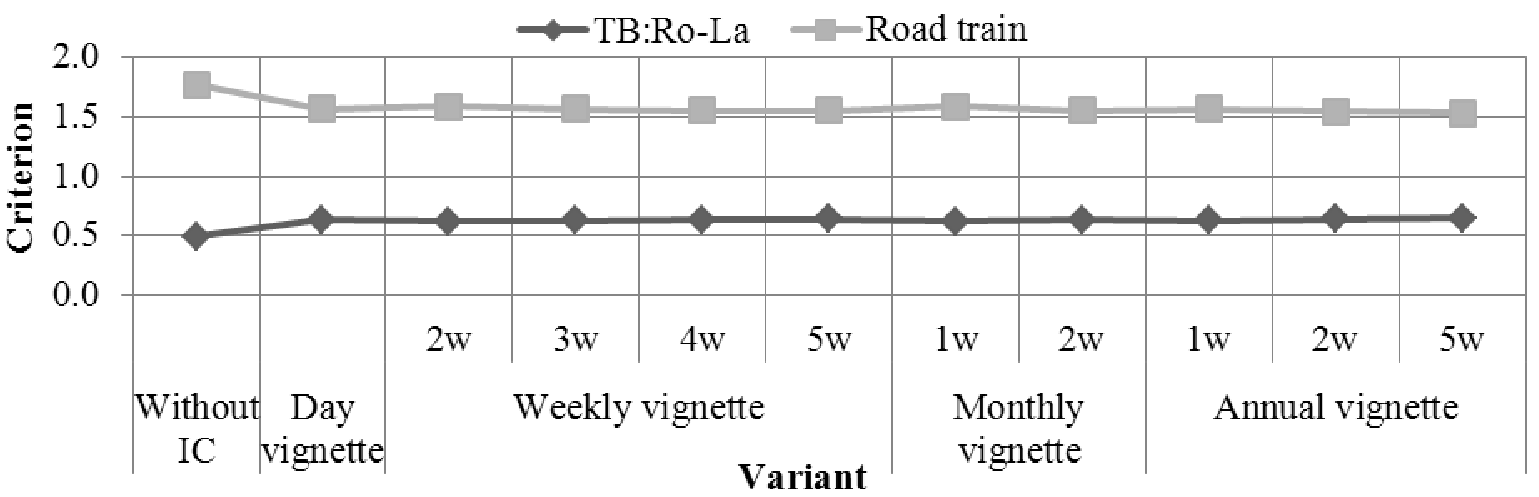

Fig. 5. Comparison of results for different variants of use of vignette for road train

\section{Conclusions}

1. In this research a multi-criterion model for evaluation of the efficiency of intermodal transport has been developed, including: identification of alternative technologies for transport in a given direction; determining the weights of criteria; prioritizing the alternatives using the PROMETHEE method; choosing an optimal alternative by complex criterion.

2. To assess the adequacy of the results a comparison of two strategies has been applied - the first uses maximum outranking flows for the criterion of optimisation, and the second: minimum of ratio of normalized costs and normalized outranking flows. The second strategy makes it possible to take into account the dynamics of changes in the components of costs, such as operating costs and infrastructure charges, when choosing the optimal variant of transportation.

3. For the surveyed routes, the number of wagons in the composition of the train, in which ecological efficiency is achieved, is determined, i.e. the emissions of pollutants from heavy goods vehicles are saved.

4. The limits of the weighting of the criteria have been established, in which the optimal solution is retained.

5. The influence of the vignette charge (by time and number of trips) on the choice of the transport technology was investigated. It has been established that for the route Sofia - Varna, when the vignette fee increase doubles, the optimal technology is the transport with container blocks trains.

6. It was found that Strategy 1 is increasing the burden of environmental criteria and both railway routes are efficient transport alternatives. 


\section{References}

[1] Islam D.M. Z., Zunder T., Jorna R. Performance evaluation of an online benchmarking tool for European freight transport chains. Benchmarking: An International Journal, Vol. 20, Issue:2, 2013, pp. 233-250.

[2] Abramovic B., Zitricky V., Biskup V. Organisation of railway freight transport: case study CIM/SMGS between Slovakia and Ukraine, European Transport Research Review, Vol. 8(4), 2016, pp. 27.

[3] Abramovic B., Lovric I., Supalo V. Analysis of intermodal terminals service quality in the republic of Croatia, Promet- Traffic\&Transportation, Vol. 24, No. 3, 2012, pp. 253-260.

[4] Skrucany T., Ponicky J., Kendra M., Gnap J. Comparison of railway and road passenger transport in energy consumption and GHG production, Proceedings of the "Third international conference on traffic and transport engineering (ICTTE)", Belgrade, 24-25 November, 2016, pp. 744-749.

[5] Camaj J., Masek J., Kendra M. Possibility of applying the common queue of waiting for servicing railway passengers. Proceedings of the "19th Scientific Conference on Transport Means", January, 2015, pp. 147-151.

[6] Stoilova, S., L.Kunchev. Study of criteria for evaluation of transportation with intermodal transport. Proceedings of 16th International Scientific Conference Engineering for Rural Development, May24-26, 2017, Jelgava, Latvia, pp. 349-357.

[7] Moldrik P., Gurecki J., Paszek L. PROMETHEE method and sensitivity analysis in the software application for the support of decision-making. Advances in Electrical and Electronic Engineering, 2010, pp.150-153.

[8] Macharis C., Springael J., De Brucker K., Verbeke A., PROMETHEE and AHP: The design of operational synergies in multicriteriaanalysis.: Strengthening PROMETHEE with ideas of AHP, European Journal of Operational Research, 153, 2004, pp. 307-317.

[9] Sehatpour M., Kazemi A., Sehatpour H.E. Evaluation of alternative fuels for light-duty vehicles in Iran using a multicriteria approach .Renewable and Sustainable Energy Reviews 72, 2017, 2012, pp. 295-310.

[10] Srinivasa R. Kumar D. MulticriterionAnalisis in Engineering and Management. PHL Learning Private Limited, Delhi, 2014, 266 p.

[11] European Truck Challenge ETC 2014, [online] [21.02.2017]. Available at: http://european-truckchallenge.com/downloads/etc-test-2014.pdf. 